International Journal of Engineering \& Technology, $7(2.24)(2018) 126-129$
International Journal of Engineering \& Technology
SPC
Website: www.sciencepubco.com/index.php/IJET
Research paper

\title{
3D Flow Prediction for high rise structures
}

\author{
D. Leela ${ }^{1 *}$, Babu..$^{2}$, Dasarathy A K ${ }^{3}$, S. Kumar ${ }^{4}$ \\ ${ }^{1 *}$ Associate professor, department of civil engineering, Dr. M.G.R. Educational and Research Institute University, \\ NH4, E.V.R. Periyar Road, Maduravoyal, Chennai 600095, India. \\ ${ }^{2}$ Department of Civil Engineering,MES College of Engineering,Kuttipuram. \\ ${ }^{3}$ professor Department of civil engineering,Vel tech multi tech Dr.RangarajanDr.Sakunthala engineering college, \\ Chennai - 600062, Tamil Nadu, India. \\ *Corresponding Author Email: talktoleela@gmail.com
}

\begin{abstract}
Structures more than $40 \mathrm{~m}$ are usually termed as high rise structures. It is difficult to predict the flow of wind around structures without the use of computational fluid dynamics software or wind tunnel. These high rise structures are subjected to stronger winds that can cause them to sway. So the predictions of aerodynamic loads acting on tall buildings are very important. This study aims to identify the characteristics of wind flow such high rise structures by predicting flow variables such as pressure, velocity and impacting stress etc using Ansys Fluent 18.1. The main purpose of this project is to find out : pressure around the building and velocity of wind around the building.
\end{abstract}

\section{Introduction}

Today the population in urban areas is about $50 \%$. This will be one and a half times in the coming 30 years. Therefore great importance has to be give to the urban microclimate. Depending on the orientation of the buildings the flow field around the buildings also will vary. Wind tunnel measurement is the experimental method available to predict the flow field around the buildings. Because of the high cost involved in the wind tunnel measurement, computational fluid dynamics (CFD) has become very important to predict the direction of wind flow around high rise buildings.

However, there have been very few reports on prediction accuracy of CFD simulations of the pedestrian wind environment around buildings in urban areas. Furthermore, the influence of various calculation conditions (such as size of computational domain, grid resolution, boundary conditions and selection of turbulence model, etc.)

\section{Mathematical Models}

The building has 12 storeys, length $200 \mathrm{ft}$ and width is $20 \mathrm{ft}$. The wind speed is said to be $2.75 \mathrm{~m} / \mathrm{s}$; the thermal load is $20 \mathrm{~W} / \mathrm{m}^{2}$ and the atmospheric temperature is taken to be ideal (i.e. $24^{\circ} \mathrm{C}$ ). The mathematical model has been used to compare the results of CFD simulation flow around the obstacle that placed on the surface boundary layer using various turbulence models as following case.

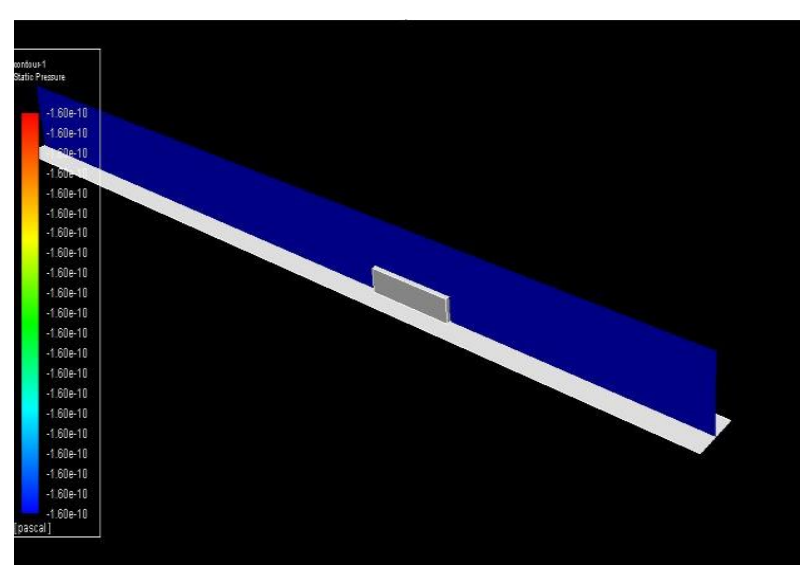

Fig. 1: geometry of the building and the domain

\section{Governing equation}

Continuity equations and the averaged Navier- Stokes equation can be used as the basis for describing the motion of turbulent airflow:

\section{$\delta_{\mathbf{v}_{\mathrm{i}} / \delta \mathbf{x}_{\mathbf{j}}=\mathbf{0}}$}

$v_{j} \delta v_{i} / \delta x_{j}=-(1 / \rho) \delta p / \delta x_{i}+\delta / \delta x_{j}\left(v \delta v_{i} / \delta x_{j}-u_{i} u_{j}\right)$

Where $\mathrm{v}$ and $\mathrm{p}$ represent fluid mean velocity and pressure, respectively; $\rho$ is the fluid density and $v$ is the kinematics viscosity. The standard $\kappa-\varepsilon$ turbulence model is used here in the form

$\mathbf{V}_{\mathbf{j}} \delta \kappa / \delta \mathbf{x}_{\mathbf{j}}=\delta / \delta \mathbf{x}_{\mathbf{j}}\left(v_{\mathbf{i}} \delta \kappa / \sigma \kappa \delta \mathbf{x}_{\mathbf{j}}\right)+v_{i}\left(\delta v_{i} / \delta x_{j}+\delta v_{j} / \delta x_{j}\right) \delta v_{i} / \delta x_{j}-\varepsilon$ (3) 


\section{Numerical Simulations}

Case A (1:1:2 Shaped Building Model) The geometry and computational domain of high rise building in wind flow are shown in Fig. 2 that used by ANSYS-ICEMCFD 14.0.

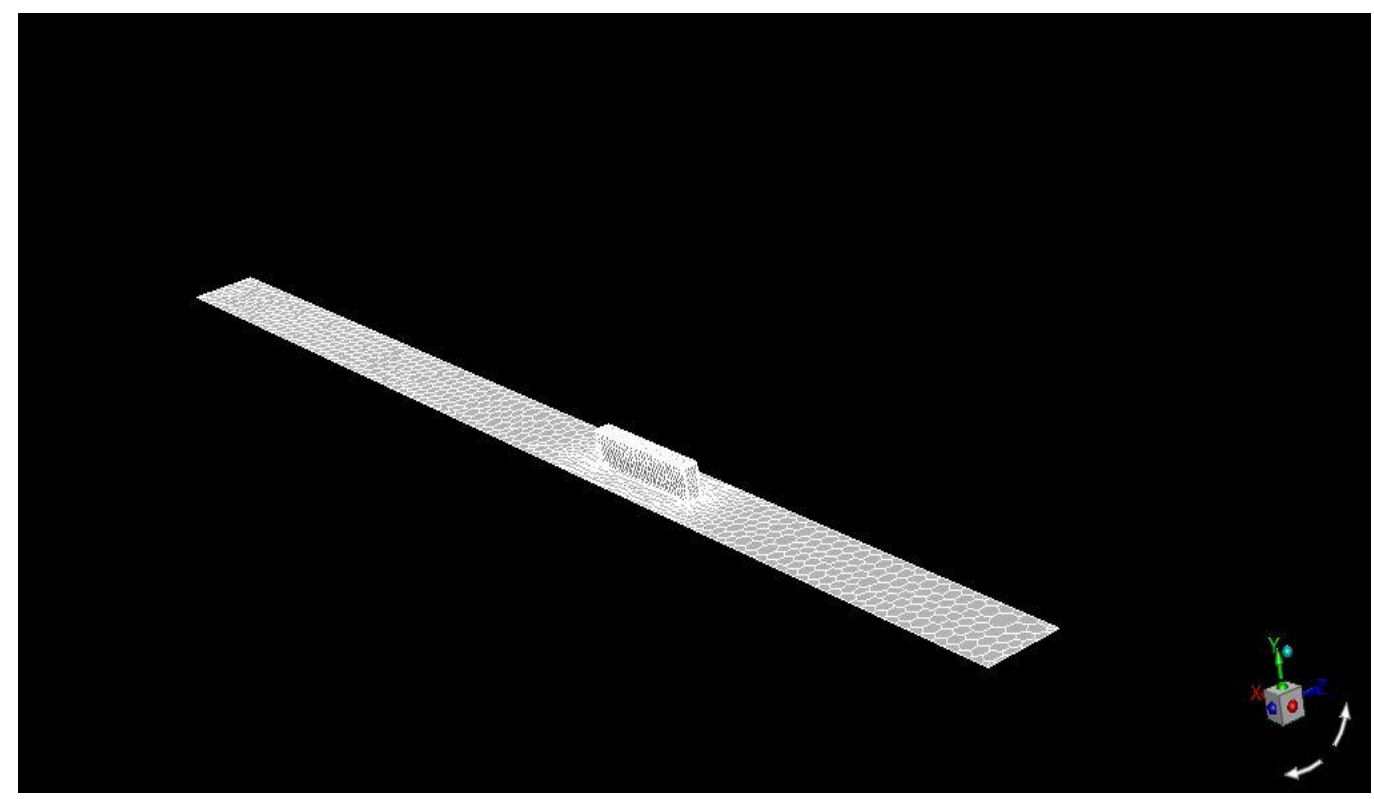

Fig. 2: Building mesh

Meshing is done in polyhedral shapes. The total elements of meshing are 1.2 millions. Incompressible, 3D steady flow two-equation of RANS equations were implemented to solve the turbulence flow. The two-equation turbulence models considered in current study are standard $\kappa-\varepsilon$, RNG and realizable. Also, second scheme is recommended for all convection terms

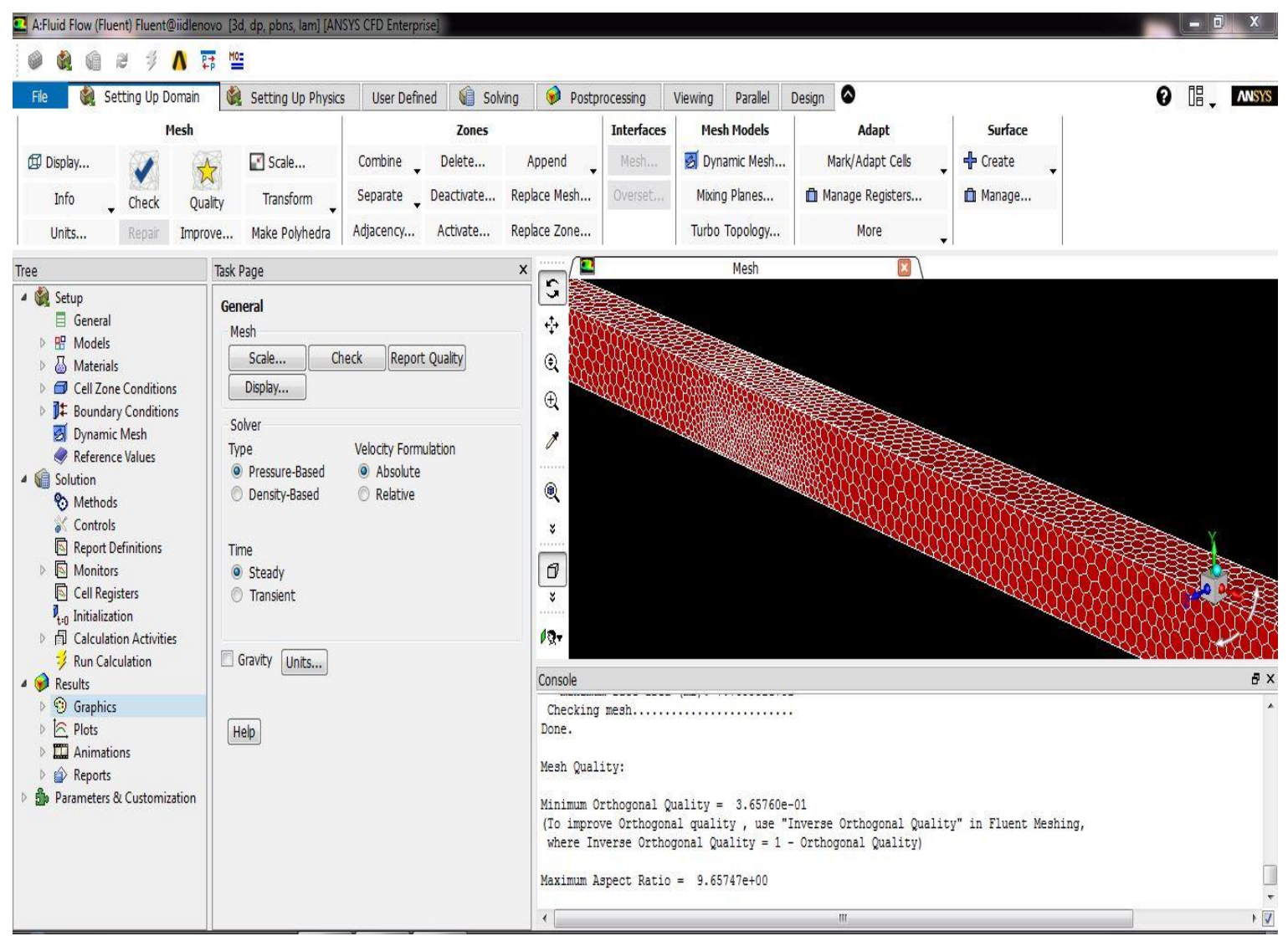

Fig. 3: Building mesh with domain. 


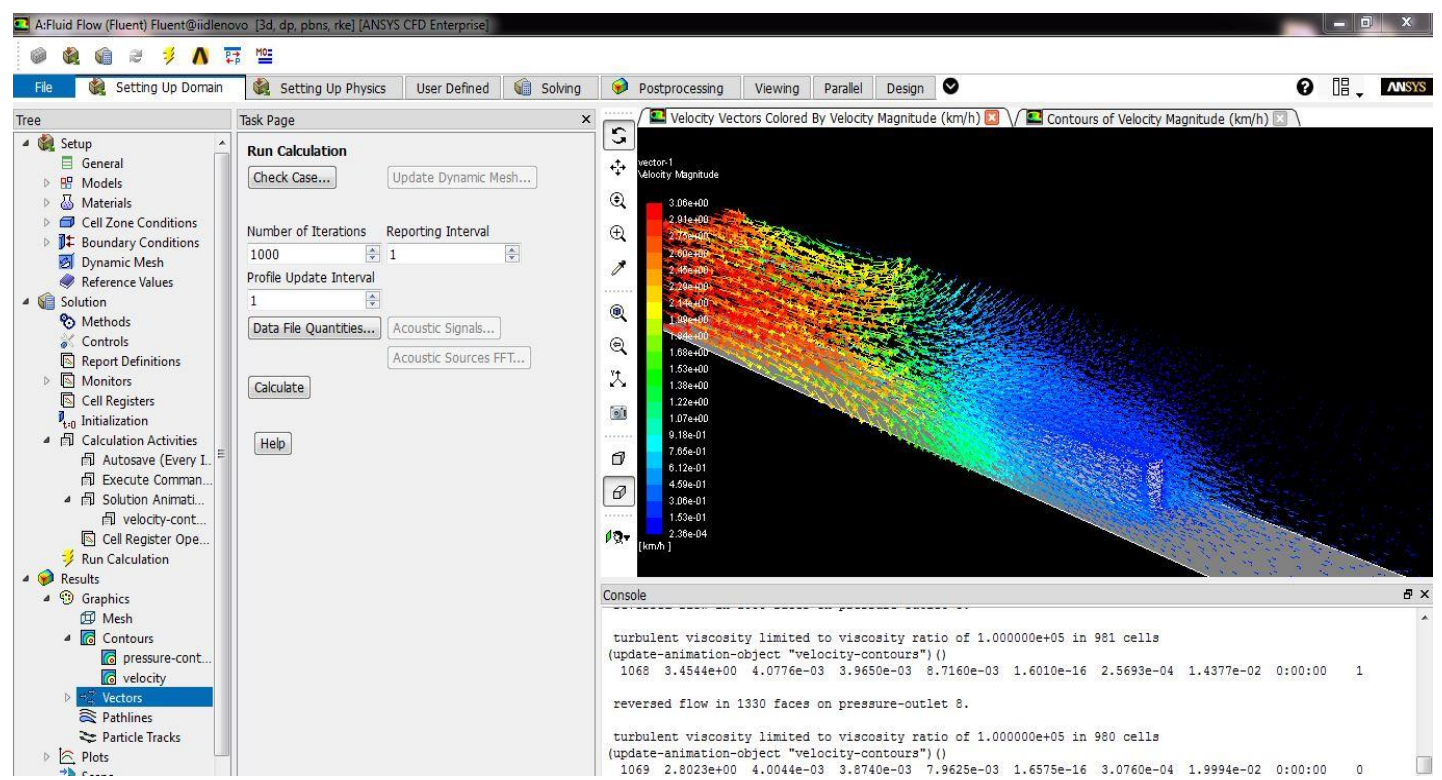

Fig. 4: Direction of velocity flow and turbulence

\section{Results}

The results obtained through analysis using CFD is shown in graphs below. Pressure and velocity are depicted in a graph versus height of the structure.

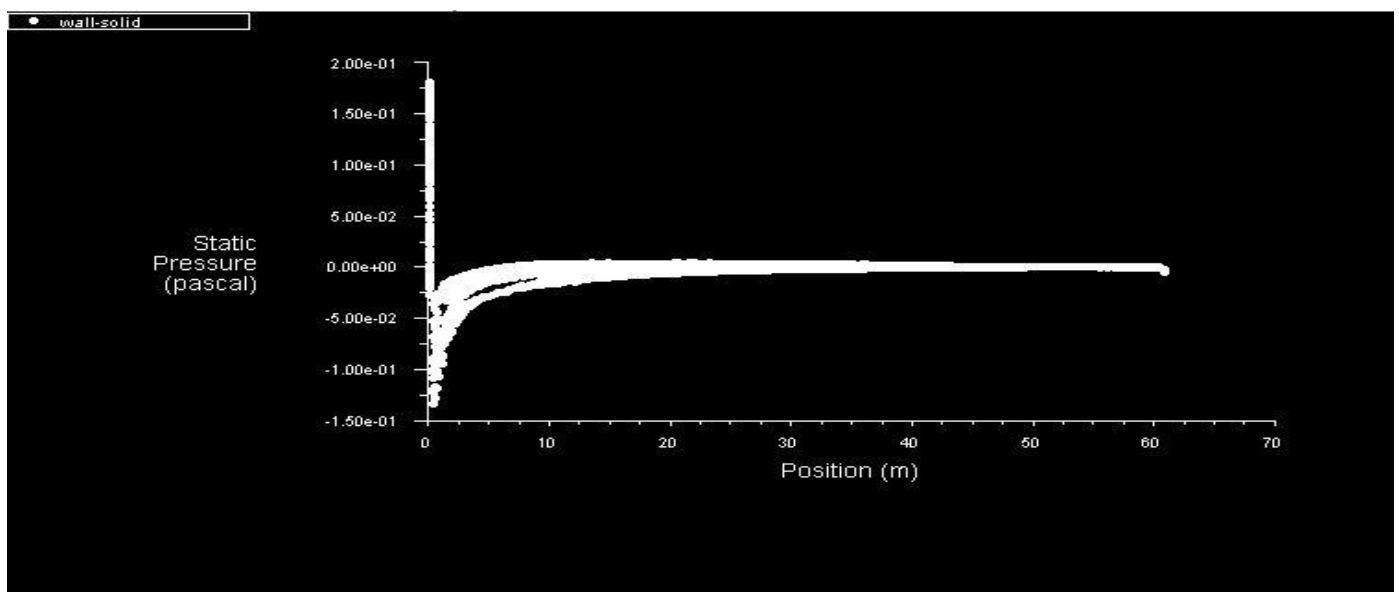

Fig. 5: pressure variation with respect to height

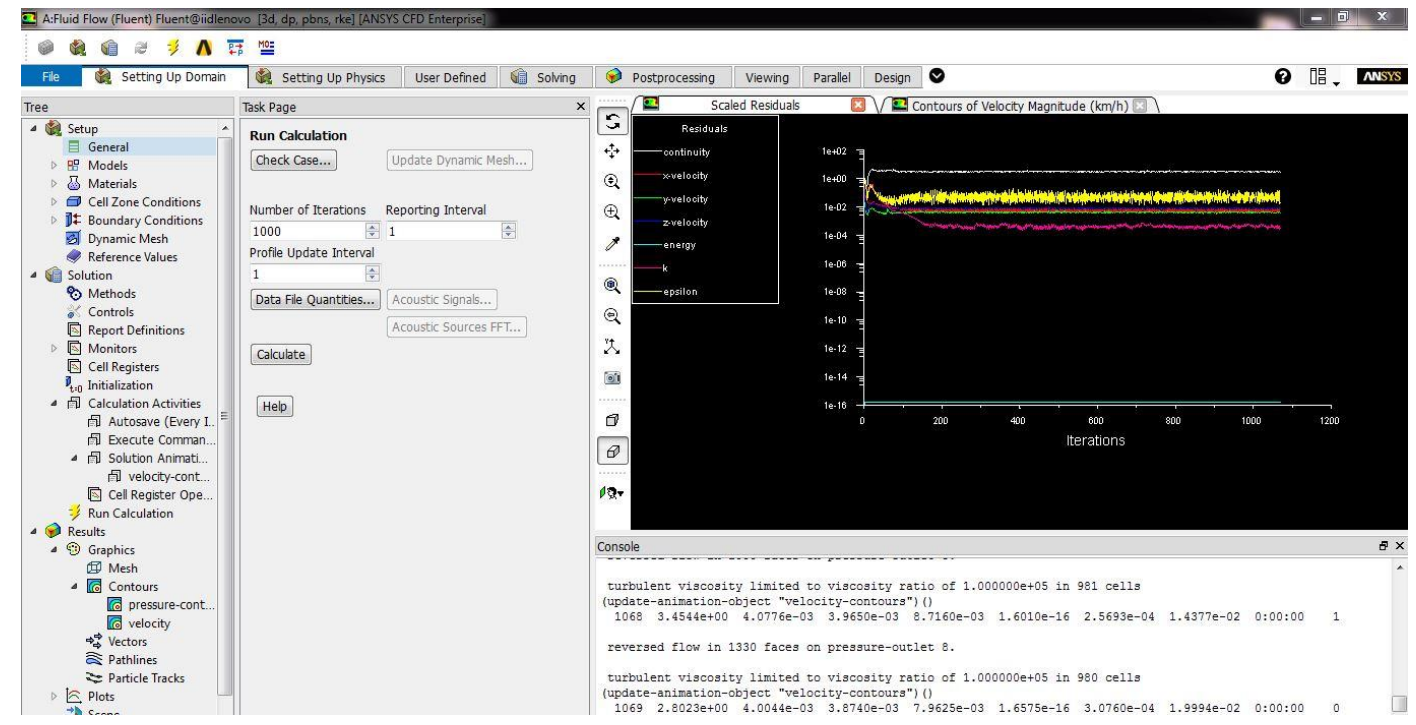

Fig. 6: velocity variation with respect to height 
From this study, the overall conclusion that can be made is that the flow characteristic and behaviour of wind around high-rise buildings can be seen through the use of the ANSYS Fluent software.

Over all conclusions were

- The orientation of the buildings is an important concern while analyzing high rise buildings.

- By finding the pressure difference of various positions in the buildings, we could be able to arrive the best locations for ventilation.

- Overall Ansys CFD 18.1 is highly recommended for fluid flow prediction around buildings.

\section{References}

[1] Holmes, J. D., 2007. Wind Loading of Structures. 2 ed. s.1.:Taylor and Francis Group. Malaysian Meteorological Department, 2013. Official Website Malaysian Meteorological Department. [Online] Available at: http://www.met.gov.my/index [Accessed 172 2015]

[2] Sato, M. \& Takaya, K., 2012. A fundamental study of the flow past a circular. SIMULIA Community Conference, pp. 1-5.

[3] Osbourn, D. \& Greeno, R., 2007. Mitchell's Introduction to Building 4th Edition. 4 ed. s.l.:Pearson Education Limited.

[4] Simiu, E. \& Scanlan, R. H., 1996. Wind Effects on Structures. s.1.:A Wiley-Interscience Publication

[5] Varkute, N. S. \& Maurya, R., 2013. CFD Simulation in Township Planning- A Case Study. International Journal of Computational Engineering Research, 3(3). 